\title{
PLASTIC DISPROPORTIONATE COLLAPSE AT LOST CORNER COLUMNS
}

\author{
Colin GURLEY
}

TAFE Civil Engineering, Sydney Institute, Ultimo, 2007, NSW, Australia

Keywords: Progressive collapse, disproportionate collapse, earthquake, robust building, Ronan Point, Oklahoma City, World Trade Center, lost support, lost column, terrorist bomb, double-span mechanism, fire, yield-line analysis, plastic analysis, bimoment, Hillerborg

\section{ABSTRACT}

This paper deploys an existing method for the simple rigid-plastic hand calculation of slab yieldline mechanisms to address the wider problem of disproportionate collapse at lost columns in multistorey buildings. Floor systems will be treated as grillages combining torsion-free (Hillerborg) slabs and torsion-free beams. The aim is to achieve an understanding that transcends reliance on non-linear finite element software but does not compete with it. This paper deals with lost corner columns which are the columns most at risk; the approach can be extended to other columns.

\section{BACKGROUND}

The UK Government introduced the first regulations on 'disproportionate collapse' soon after the Ronan Point collapse of 1968. Versions of the UK regulations were then adopted in other countries and interest has been heightened again by the terrorist attacks on the Murrah Federal Building in Oklahoma City 1995 [1] and the World Trade Center 2001 [2,3].

The current version of Approved Document A; Requirement A3 Disproportionate Collapse [4] at $<w w w$. planningportal.gov.uk> includes, at clause $5.1 \mathrm{~d}$ :

- "Alternatively, check that upon the notional removal of each supporting column and each beam supporting one or more columns, or any nominal length of load-bearing wall (one at a time in each storey of the building), the building remains stable and that the area of any floor at any storey at risk of collapse does not exceed 15\% of the floor area of that storey or $70 \mathrm{m2}$, whichever is smaller, and does not extend further than the immediate adjacent storeys."

This provision (almost 40 years ago) first defined the notion of what I now describe as 'lost column' analysis.

Earthquakes can also remove columns (often corner columns) so that earthquake engineering also needs to include 'lost column' analysis[5]. Indeed, there is much to be said for merging design against disproportionate collapse with design against earthquakes so as to rationalise (maybe even simplify) numerous areas of overlap[6]. NIST seems to want to go further and include fire engineering in an over-arching structural design assessment of the response of tall/important buildings to multifacetted 'abnormal events'[7]. Earthquakes and explosions do, often enough, cause fires and earthquakes (and fires) are often followed by after-shocks and fire-fighting may be then impeded by earthquake or explosion damage to water-supply and to active fire-protection systems.

The FEMA/ASCE Report on The Oklahoma City Bombing concluded that, for a new but otherwise identical building, special ductile earthquake detailing as described in $\mathrm{ACl} 318$ Chapter 21 (or, one assumes, NZS 3101) would have reduced the damage (and perhaps fatalities) by $80 \%$ at an extra cost of $1 \%$ to $2 \%$ of the total cost of the building. Ductile detailing is usually implemented only for projects in regions of high earthquake risk (such as California and New Zealand) but it can be applied anywhere:

- Ductile detailing is a separate issue to that of design lateral loads; there is no problem in using ductile detailing with plastic hinge strengths calculated for wind load

- Ductile detailing is an appropriate conjunct to any form of plastic design.

GSA 2003[8] documents the first American version of 'lost column' analysis for application in the design of new US Federal buildings. GSA 2003 is more detailed than the UK Requirement A3. It does seem somewhat pre-occupied with car/truck bombs and so it assumes that columns (or other loadbearing structure) can only be lost in a storey on about the same level as an exterior pavement or 
interior uncontrolled parking. The 'lost support' at Ronan Point was at about mid-height of the building and columns can be lost to earthquakes in any storey.

GSA 2003 does include useful material on the gravity loads and load-factors to be considered with 'lost column' analysis and a helpful discussion on 'double span' mechanisms.

For 'lost column' analysis GSA does allow:

- Reduced gravity loads and load-factors during abnormal events

- Increased DCR (Demand/Capacity Ratios) > 1 (due to material over-strength and strain hardening) similar to those used for earthquake assessment of existing buildings. This makes sense but is an issue on which UK Requirement A3 is silent.

The two major studies on the World Trade Center are:

- FEMA 403/ASCE 2002, World Trade Center Building Performance Study

- NIST 2005 Final Report on the Collapse of the World Trade Center Tower

Both contain a wealth of engineering wisdom and numerous insights related to 'disproportionate collapse'.

NIST introduced the phrase 'progressive collapse' as a synonym for the UK phrase 'disproportionate collapse'. Suffice it to note that both towers resisted 'disproportionate collapse' for about one hour after impact saving many lives notwithstanding the loss of more than 30 adjacent façade columns in each tower and several core columns. The two most important suggestions of the NIST study are, I suggest, that:

- Tall buildings should not generally be designed for aircraft impact but notwithstanding that;

- There should be a searching review of the role and performance of the two types of thermal insulation used in the World Trade Center to re-define satisfactory performance "over the life of the building":

o SFRMs (sprayed fire-resisting materials) for steel beams, trusses and columns and

o Gypsum wall-board for core elements including steel columns, fire-escape stairs and fire-escape corridors

What is at issue is not, so much, whether these insulation materials satisfactorily insulate in a laboratory test furnace but whether they are likely to survive other exigencies and be around and able to fulfil their task in a real fire. Fire insulation is now to be regarded as an essential structural component subject to all of the appropriate quality controls during construction and "over the life of the building".

\section{INTRODUCTION}

The purpose of this paper is to consider the analytical tools to be used for 'lost column' analysis. It seems helpful, first of all, to separate catenary action from flexural grillage action. Non-linear finite element programs should be able to reliably track both with, perhaps, catenary action taking over a larger share of strength as deflections increase. The aim here is understanding rather than reliance on software.

Catenary action seems likely to be sensitive to the position of the 'lost column' within the building with 'lost corner columns' the least likely to benefit from catenary action. Corner columns are also, as it happens, the most likely to be lost in an earthquake.

Furthermore, catenary action is not likely to be calculable with simple rigid-plastic hand calculations on a pocket calculator. Flexural grillage action is likely to be so calculable. There is a role for simple hand calculations to inform engineering judgement and to confirm that the output of nonlinear finite element programs is of the right order of magnitude.

The first purpose then is to re-examine the tools for the plastic analysis of slabs and grillages.

\section{PLASTIC ANALYSIS OF SLABS AND GRILLAGES}

Plastic analysis admits 2 kinds of solution. As Mikael Braestrup[9] has been wont to put it (from memory):

- Upper bound solutions: If a structure can find a way to collapse (meaning a valid collapse mechanism) then it will. Upper bound solutions always over-estimate strength.

- Lower bound solutions: If a structure can find a way to stand (meaning a valid equilibrium solution) then it will. Lower bound solutions always under-estimate strength. 
The first form of plastic analysis for slabs was that usually ascribed to $\mathrm{K} \mathrm{W}$ Johansen although there were other Danes involved as far back as 1920. Johansen yield-line analysis[10,11]:

- Provides only upper-bound solutions

- Assumes that slab-segments between yield-lines remain plane although those planes may be of small extent as with a conical mechanism

- Is simple enough to appreciate but can involve some horrendous algebra/calculations mostly because of the complex collapse geometry

The second form of plastic analysis for slabs was the Strip Method of Design by Arne Hillerborg[12] of Lund in Sweden which:

- Provides only lower-bound solutions

- Assumes that the slab torsional moments $m_{x y}$ and $m_{y x}(\mathrm{kNm} / \mathrm{m})$ are everywhere zero so that the load is carried by torsionless strips parallel to each of the 2 rebar directions

- Can also lead to some horrendous complexity because of the difficulty of formulating complete equilibrium solutions without the insight that collapse mechanisms can provide.

Hillerborg's Strip Method treats slabs as torsion-free grillage continua. This implies a physical model of slab segments which can displace into hypar (hyperbolic paraboloid) shape between yield lines without any internal work in a virtual displacement or in a mechanism[13,14,15]. This implies an extra set of stress-resultants with their own equilibrium conditions which I call 'bimoments' $\left(\mathrm{kNm}^{2}\right)$. Hillerborg slabs are less redundant (less statically indeterminate) than Johansen slabs and so easier to calculate.

The 'bimoment method' applies upper-bound collapse-mechanism methods to Hillerborg slabs. This leads to calculations which are much simpler and to solutions which are sometimes just a few percent lower than the Johansen solutions, sometimes to solutions which up to about $30 \%$ lower. The bimoment method also clarifies the two different strip methods proposed by Hillerborg:

- Hillerborg's simple strip method deals with problems in which the bimoment method provides solutions which are 'exact' in that they satisfy both upper- and lower-bound conditions within the assumption of torsion-free behaviour.

- Hillerborg's advanced strip method addresses problems in which the bimoment mechanisms lead to nodal forces involving infinite transverse shear-stresses. This includes all of the 'difficult' problems involving near-point loads and supports.

No two-dimensional method of plastic flexural analysis for 'thin' slabs has ever attempted to deal with slab shear-strength and, clearly, this involves more complex issues that would have to be dealt with in three-dimensions. It is encouraging then that, even for Hillerborg 'advanced' problems, one can often find lower-bound strip solutions at, say, $90 \%$ of the strength predicted by a well-conceived bimoment mechanism.

The remainder of this paper will deploy the bimoment method to the simple rigid-plastic analysis of lost corner column problems. This will include the contribution, not only of the slab but also of whatever grillage of intermediate beams exists in the corner bay in either or both of two orthogonal directions. This includes, for example, 'waffle' floors with any beam/rib spacing in either or both directions.

\section{ASSUMPTIONS AND LIMITATIONS}

This paper is limited to the usual case of framing beams and slab reinforcement in each of two perpendicular directions parallel to the façades of the building. Layouts involving diagonal framing may sometimes be more efficient but they cannot be dealt with by these methods. Cases involving two framing directions not at right angles (as in a skew bridge) can probably be dealt with by bimoment methods but I have never tried to do so.

Beams are to be considered composite with the concrete slab whether concrete beams or steel Ibeams (UBs). These beams will normally undergo hogging (negative $=$ tension top) moments where they cross the yield-lines. The flange-width for negative bending should be that specified by the relevant code (BS 8110 or BS 5950). The top flange provided by the slab will usually be a good deal wider than the web-width at the bottom/compression face. The moment capacity provided by rebars within the flange-width of the beams should be calculated at the effective depth of the composite beams. Obviously such rebars cannot be double-counted by including further moment capacity at the effective depth of the slab. 
There are cases, including the World Trade Center, in which floors spanning to a column lost in some storey below were clearly hanging from stronger structural elements at some higher level. Simple statics dictates, however, that this cannot happen unless there is some stronger structure above or, perhaps, some that is of equal strength but more lightly loaded. If all floors are of identical strength and gravity load then they will all stand or fall together and there will be near-zero axial forces in the column above the lost storey.

Columns in storeys above the lost column may, however, develop beneficial bending moments associated with Vierendeel action in the floors. The limiting strength then may involve threedimensional failure at the floor-column connection. There is no adequate plastic theory for dealing with this but codes of practice contain empirical prescriptions for column-floor connections. Later we will discuss how such connection strengths can be included in the bimoment analysis.

Thus the procedure proposed is:

- Calculate the strength of each typical floor as if an isolated floor unsupported by the corner column

- Modify that strength to include the beneficial Vierendeel effect of column moments noting that this will lead to small axial forces in the column

- If the collapse strength thus calculated is inadequate then modify the analysis again so as to calculate the support force that the column must provide at each floor in order to avoid a disproportionate collapse

- If necessary, sum the column support hanging force for all floors above the lost column up to the roof and

- If necessary, provide some special structural elements near the top of the building to support the hanging columns

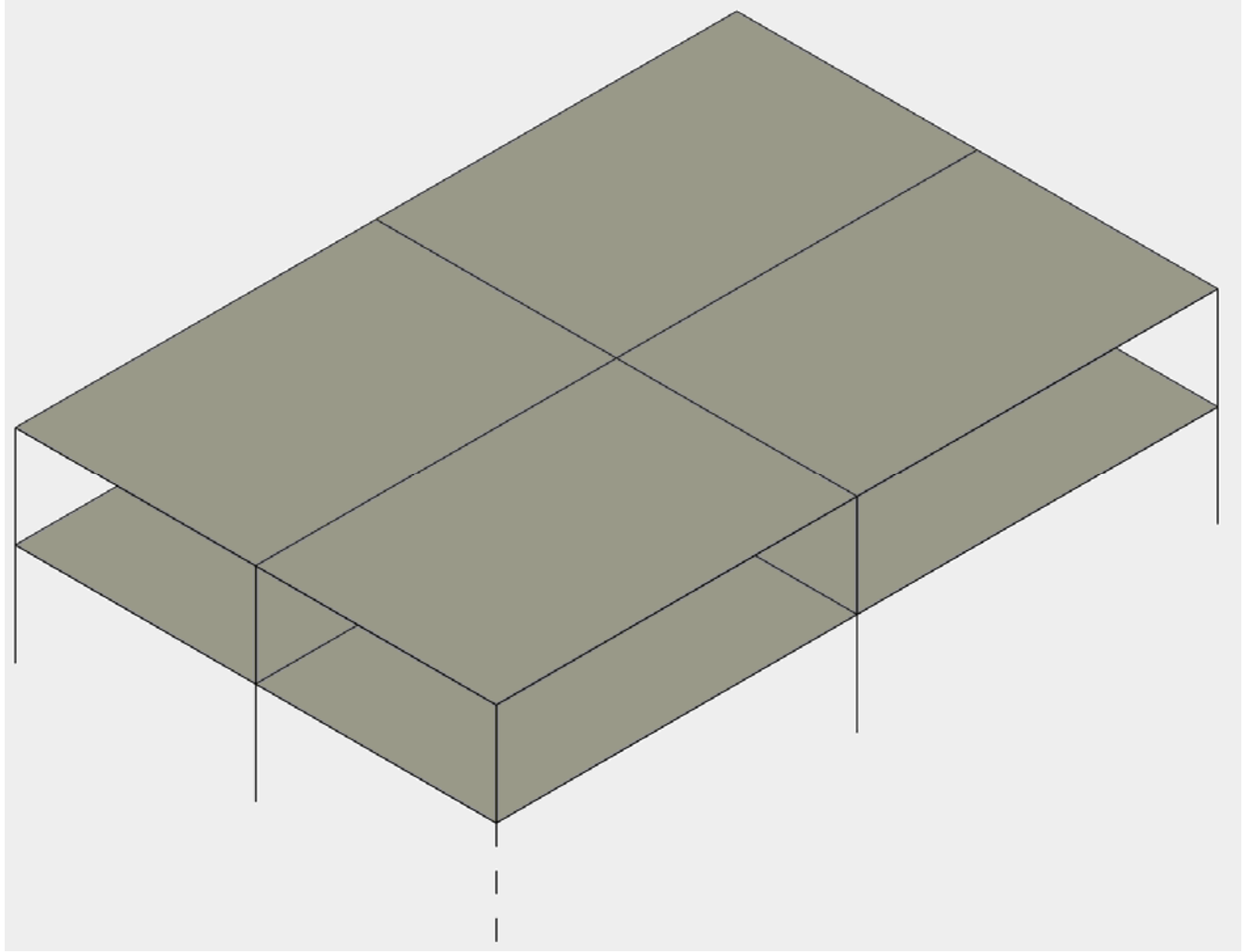

Fig. 1 Whole building 


\section{OVERTURNING BIMOMENT OF THE LOADS}

Fig 1 shows an isometric view of an example building of 2 bays in each direction and 2 storeys with a lost corner column in the lowest storey. This is merely an example: buildings may have any number of bays and any number of storeys and columns can be lost in any location and in any storey.

Fig 1 shows beams in both directions on the column centre-lines. This too is merely an example; there need be no beams at all or there can also be intermediate beams between column centre-lines in either or both directions.

Fig 2 shows a collapse mechanism with yield-lines on the 2 adjacent supported edges of the corner bay at both levels.

Fig 3 shows more detail of the corner bay. The $x y$-coordinates follow the framing directions and the origin is at the nearest interior column. The entire bay displaces into a hypar (hyperbolic paraboloid) shape:

$$
z=t x y
$$

where $t$ is a scale factor of dimension 1/length.

Fig 3 also shows a representative point load $W$ at co-ordinates $(x w, y w)$. Then the virtual work done by the load during the displacement $z$ is:

$E=W z=t * B_{o}$ where : $B_{o}=W x_{w} y_{w}$

is the overturning bimoment of load $W$ about the origin of the hypar.

The total (overturning) bimoment of all loads will be the sum of the bimoments of each distinct load. Normally loads are distributed over a rectangular area or along the length of a line. So long as these rectangles and line segments are parallel to the framing directions, it is correct to replace them by the total force acting at the geometric centre of the load concerned. Loads such as a wall running along a line at some other angle to the framing directions:

- are unusual

- can be expressed as a double integral but I have never had to do that instead

- are best handled as a sequence of distinct point loads which amounts to numeric integration

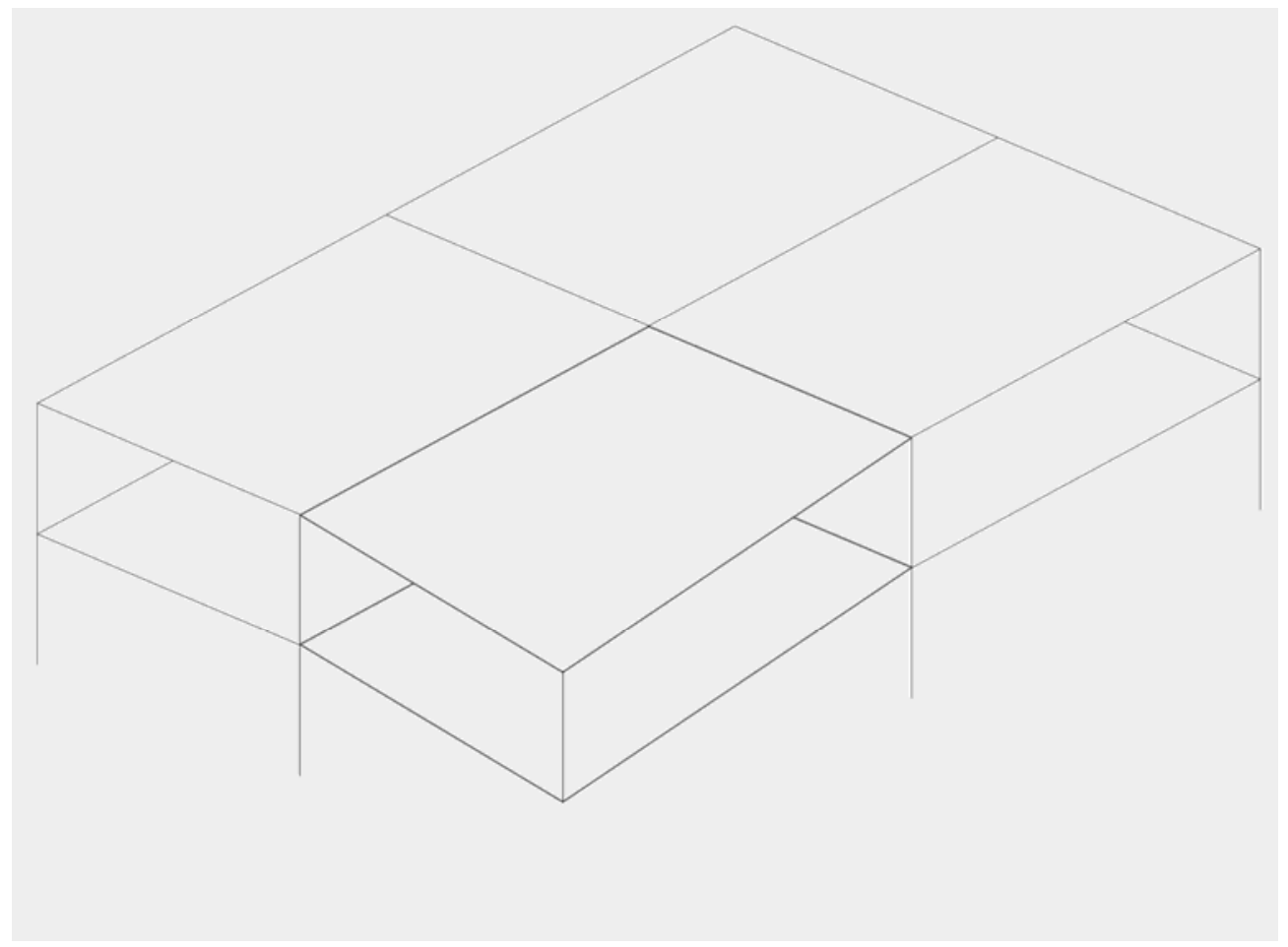

Fig. 2 Mechanism in corner bays 


\section{RESTORING BIMOMENTS OF THE YIELD RESISTANCE MOMENTS}

\section{8}

Fig 4 shows the mechanism with concentrated resistance moments acting across each yield-line:

$M_{X}$ at co- ordinate $y_{m}$

$M_{y}$ at co- ordinate $x_{m}$

The plastic rotations at each moment will be:

$\theta_{x}=t y_{m}$

$\theta_{y}=t x_{m}$

and the work done by the moments at the yield lines:

$D=t^{*} B_{r}$ where

$B_{r}=B_{X}+B_{y}$

$B_{X}=M_{X} * y_{m}$

$B_{y}=M_{y} * x_{m}$

$B_{r}$ is the sum of the restoring bimoments $B x$ due to $M x$ and $B y$ due to $M y$.

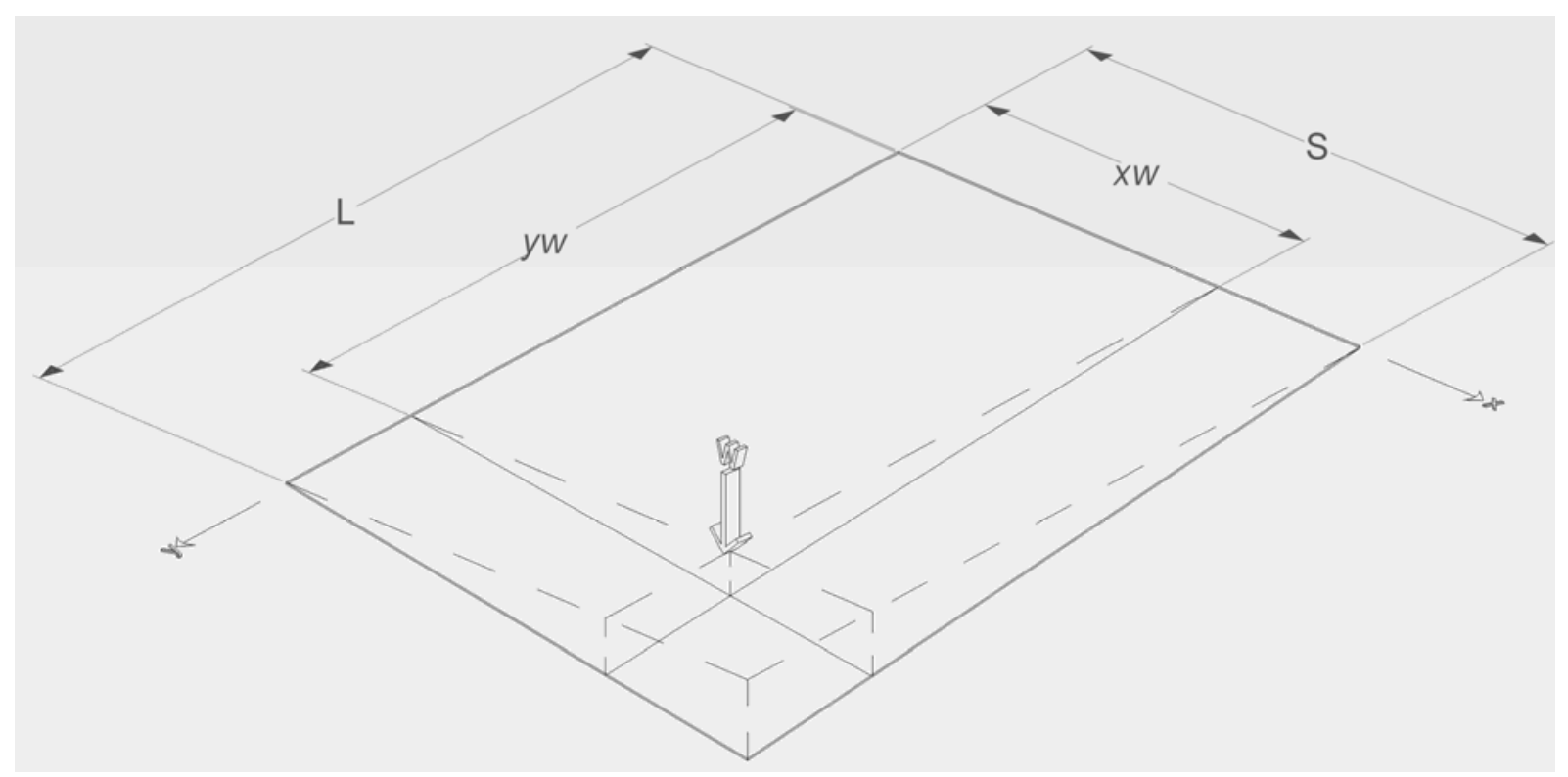

Fig. 3 Detail of corner bay with a representative point load 


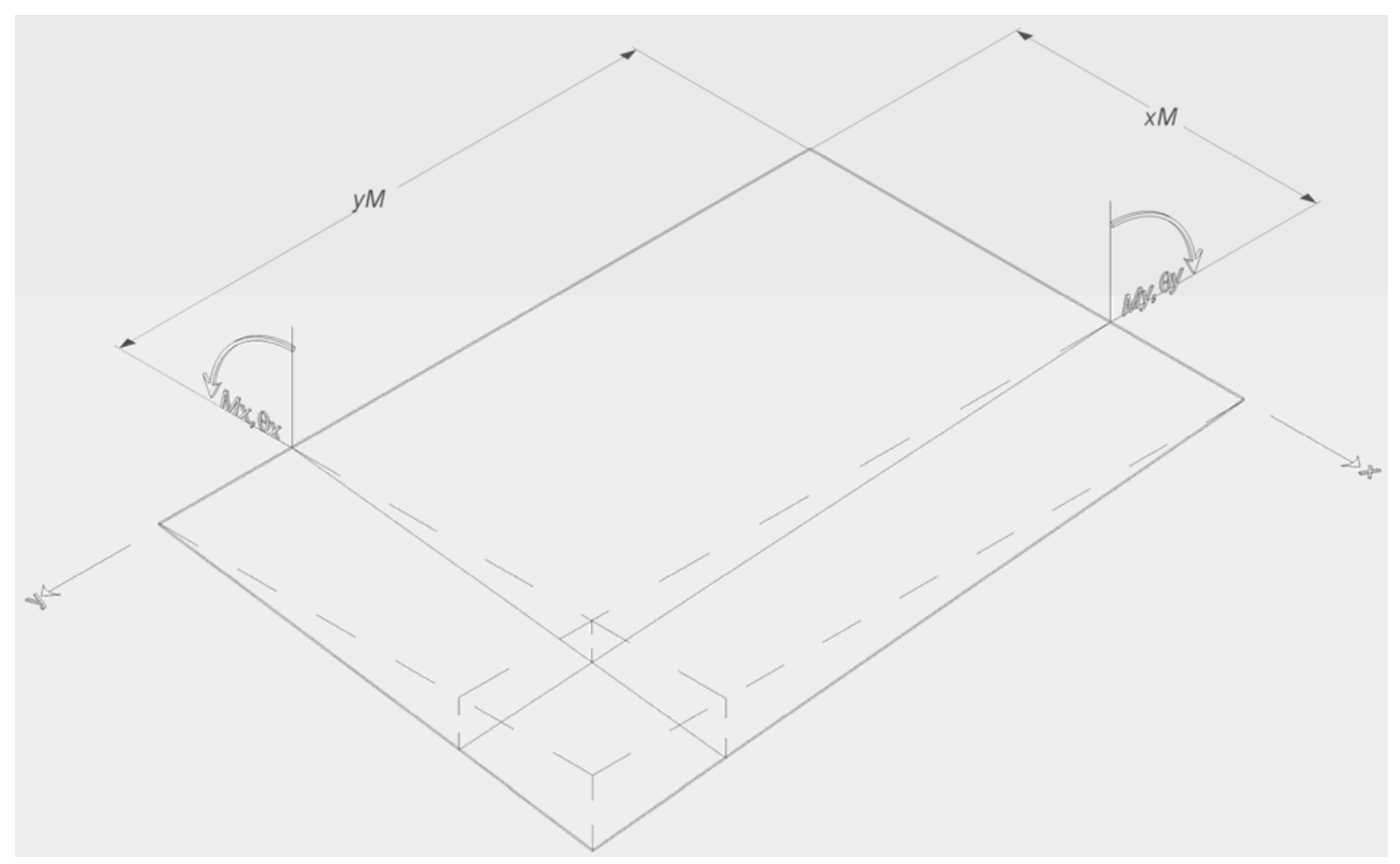

Fig. 4 Representative yield resistance moments

In general, several strips in each direction will be required to define the solution. There will usually be rather fewer strips than used by Hillerborg but there must be, at least enough to distinguish the flange areas of the beams from intervening strips of slab (if any) acting just as slabs.

For any strip with uniformly distributed rebars, including the top flanges of composite beams, it will be correct to lump the moment of resistance at the centre of the strip. Note also that slab bottom rebars can sometimes act as beam top rebars because of the different depths involved.

Then the total restoring bimoment of the reinforcement will be the sum of the bimoments for each strip including 2 directions.

Edge L-beams (actually inverted $\mathrm{L}$ ) are a particular problem which, to the best of my knowledge, has not yet been addressed by the research community. For negative moment (tension top) the forces making up the internal couple are not in the same vertical plane:

- The centroid of the top tension flange force will be the centroid of the rebar

- The centroid of the bottom flange force will be close to the centre of the web or bottom flange.

Perhaps L-beams provide a moment of resistance in an inclined plane and the support to the slab is rectified by diaphragm forces in the slab.

This is an intriguing problem to which I would like to find the answer.

As an interim measure, it would seem safe to lump the moment strength of the edge-beams at the centroid of the top flange rebar.

\section{SOLUTIONS}

The statement:

$B_{o}=B_{r}$

can now seen to provide a kinematically correct upper-bound solution for the collapse load using the virtual work method[16].

Complying lower-bound strip solutions can be found providing that there is a reasonably strong beam on, at least, one of the interior $x y$ axes of the collapse hypar. Thus I exclude only beam-less 'flat-plate' structures. Excluded cases are in the more difficult 'advanced' category of Hillerborg involving nodal forces and infinite shear stresses at the mechanism load. Even then, I think that it will be possible to find lower-bound solutions at, say, $90 \%$ of the mechanism value. 
As a simple demonstration, consider a uniform slab which has no beams crossing the yield-lines of Figs 2 and 3 but beams of ample strength along the interior edges of the hypar. Assume a uniform area-load $w(\mathrm{kPa})$ throughout, and uniformly distributed slab yield flexural strengths $m x$ and $m y$ $(\mathrm{kNm} / \mathrm{m})$ :

$$
\begin{aligned}
& W=w L S ; x_{w}=L / 2 ; y=S / 2 \\
& B_{O}=w L^{2} S^{2} / 4
\end{aligned}
$$

Then: $M_{X}=m_{X} * L ; y_{m}=L / 2 ; M_{y}=m_{y} * S ; x_{m}=S / 2$

$$
\begin{aligned}
& B_{r}=m_{x} L^{2} / 2+m_{y} S^{2} / 2 \\
& w=2 m_{x} / S^{2}+2 m_{y} / L^{2}
\end{aligned}
$$

This is an upper-bound solution above leading to the exact lower-bound solution below with just one strip in each direction:

$$
\begin{gathered}
w_{x}=2 m_{x} / S^{2} \\
w_{y}=2 m_{y} / L^{2} \\
w=w_{x}+w_{y}
\end{gathered}
$$

\section{MOMENT-FREE COLUMNS}

If a bimoment analysis shows that the typical floor can carry the 'abnormal event' gravity load without assistance from the corner column then disproportionate collapse has been averted and there is no need for any further analysis. Otherwise, the next simplest stage to consider is that of a hanger column assumed to have negligible moment strength.

The hanger force $\mathrm{H}$ is simply an upward vertical force located at column co-ordinates $(x c, y c)$ near but not at the corner $(S, L)$.

The bimoment of the column hanger force must then be:

$H x_{C} y_{C}=B_{O}-B_{r}$

- where $B o$ is calculated from the 'abnormal event' gravity load and

- $B r$ is the restoring bimoment provided by the floor system at, perhaps, over-strength yield.

The hanger force must be transmissible into the body of the floor without any shear-failure localized around the column connection. This is a matter which should be addressed using the relevant empirical procedures of BS 8110 or other applicable code. One would normally expect that edge-beams framing into the column in either direction would preclude any such problem.

\section{COLUMNS WITH BIAXIAL MOMENT CAPACITY}

Columns in general have a complex relationship between axial load and biaxial moment strength. Moments in either direction transmitted from the column must appear as sagging (positive $=$ tension bottom) moments in the floor if they are to be helpful. Once again any combination of hanger force and biaxial moment transmitted into the floor must be within the local shear-strength provisions of BS 8110 or other applicable code.

The bimoment method does not address the strength of columns but, in so far as the floor is concerned, it just wants bimoment support from a hanger force or from column moments in either/both directions:

$$
\begin{aligned}
& B_{H}=H x_{c} y_{c} \\
& B_{C x}=M_{C x} * y_{C} \\
& B_{c y}=M_{c y} * x_{C}
\end{aligned}
$$


The floor cares only about the total of these 3 contributions and realizing this does help to simplify consideration of the axial/biaxial strength of the column.

Note that the lowest floor (immediately above the lost column) and the highest (the roof) will have columns above (and below) only so the moment strengths available from the column will be about half of the strengths available at intermediate floors.

Note also that Virendeel action with column moments does require double-curvature bending of columns with column shears which will be transmitted to the floors as horizontal in-plane forces. I don't think that these are likely to be significant but, of course, one must always keep track of static equilibrium.

\section{CONCLUSION}

The 'bimoment method' for the plastic yield-line analysis of slabs has been around since 1979 and has some users in New Zealand, Australia, Europe and Cambridge.

This paper has described the use of the method for the simple rigid-plastic flexural analysis of whole floor systems (slabs and beam grillages) after corner columns have been lost to accidents (gas explosions or vehicle impacts), earthquake or terrorist attacks.

Some will prefer to rely on nonlinear finite element software to fulfil this need. Others will also look for simple 'back of an envelope' calculations just so as to be satisfied that the software is producing answers that make sense.

Lost corner columns seemed both the more crucial case and the easiest to deal with. The method can clearly be extended to façade columns and interior columns and I will try to do that soon. Alas it cannot deal with catenary action and that is an inherent limitation.

\section{ACKNOWLEDGEMENTS}

Thank you to my friend and colleague Orchard Somerville-Collie. Orch drew the illustrations in Google SketchUp.

Thank you also to all of the friends who have shared their thoughts and hospitality with me and my wife Julie during our rare, and usually, hurried journeys to the northern hemi-sphere.

\section{REFERENCES}

[1] FEMA 227/ASCE August 1996: The Oklahoma City Bombing: Improving Building Performance Through Multi-Hazard Mitigation. Federal Emergency Management Agency \& American Society of Civil Engineers, Washington August 1996

[2] FEMA 403/ASCE 2002: World Trade Center Building Performance Study: Data Collection, Preliminary Observations, and Recommendations. Federal Emergency Management Agency \& American Society of Civil Engineers, Washington May 2002.

[3] NIST 2005: Final Report on the Collapse of the World Trade Center Towers; National Institute of Standards \& Technology; NIST NCSTAR1; Washington

[4] Approved Document A 2004 A3 Disproportionate Collapse; The Building Regulations 2000, London. Downloadable from http://www.planningportal.gov.uk/ Click on Professional User; Click on Building Regulations; Click on Technical Guidance; Click on Part A. OR GO TO: http://www.planningportal.gov.uk/england/professionals/en/4000000000067.html

[5] Gurley, Colin 2006: Protecting life \& reducing damage in earthquakes and terrorist attacks. Proceedings AEES2006 Conference, Canberra November 2006. Australian Earthquake Engineering Society. Should soon be downloadable at www.aees.org.au

[6] Gurley, Colin 2007: Progressive collapse and earthquake resistance. submitted for publication.

[7] Gurley, Colin 2007: Structural design for fire in tall buildings. submitted for publication.

[8] GSA 2003: Progressive Collapse Analysis and Design Guidelines for New Federal Office Buildings and Major Modernization Projects, US General Services Administration.

[9] Braestrup, Mikael: Ten Lectures on Concrete Plasticity, Course given in Nanjing, China October 1982. Dept of Structural Engineering, Technical University of Denmark, Copenhagen.

[10] Nielsen, M.P. 1964 Limit Analysis of Reinforced Concrete Slabs, Danmarks Ingeniorakademi, Bygningsafdelingen, Copenhagen

[11] Jones, L.L. and Wood, R.H. 1967, Yield-Line Analysis of Slabs, Thames \& Hudson Ltd London and Chatto \& Windus Ltd London 
[12] Hillerborg, Arne 1975 Strip method of design, English edition, Cement and Concrete Association, Wexham Springs, Slough, Great Britain

[13] Gurley, C.R, 1979 Bimoment Equilibrium of Finite Segments of Hillerborg Plate, Magazine of Concrete Research, London, Vol 31, No.108, September 1979, pp 142 - 150

[14] Gurley, C.R, 1979 Limit State Design of Slabs, Proceedings New Zealand Institution of Engineers, March 1979

[15] Gurley, C.R, 1980 Plastic Design of Slabs, School of Engineering Report No 210, University of Auckland, New Zealand.

[16] Baker, Sir John and Heyman, Jacques 1969: Plastic Design of Frames 1. Fundamentals, Cambridge University Press 1969

[17] Argyris, J.H. and Kelsey, S. Energy Theorems and Structural Analysis. Butterworths, London, 85 pages, 1960

\section{APPENDIX: A NOTE ABOUT SIGNS (+,-)}

The position concerning arithmetic signs for bimoments (moments) is precisely the same as it has always been for moments in beams for the same reasons:

- The overturning bimoment is related to the virtual work done by the loads which usually involves a downward vertical force moving through a downward displacement and is intrinsically positive.

- The restoring bimoment is related to the virtual strain energy of the internal moments acting through the corresponding internal rotations[17]:

$$
D=\delta U_{i}=\int_{V}[\sigma \delta \varepsilon] d V
$$

It is clear from this equation that the sign convention for rotations should not relate to the sign convention for angles (clockwise/counterclockwise) but rather to the signs of the corresponding strains and curvatures which will normally be the same as the signs of the corresponding moments. This is the convention employed by Jones, L.L. and Wood ${ }^{11}$ and by Baker and Heyman ${ }^{16}$.

Thus a moment that is considered negative in that it produces tensile stresses in the top of a beam will normally correspond to negative (tensile) strains and curvature and so to positive strain energy. This is directly analogous to the statement that a tie in a truss will normally experience elongation while a strut will normally experience shortening. 